\title{
Entrevista ao Professor Doutor Ronai Pires da Rocha
}

Por: Cláudia Cisiane Benetti

Cláudia: Gostaríamos de iniciar por uma questão que é sobre sua trajetória intelectual, sua formação e sua relação com a Educação e, em especial, com o Ensino da Filosofia. Pode nos falar brevemente sobre isso?

Ronai: Minha formação é em Filosofia. Fiz minha licenciatura e o mestrado na Universidade Federal de Santa Maria. Fiz o Doutorado na Universidade Federal do Rio Grande do Sul. Comecei minha vida de professor muito cedo, ainda quando fazia a licenciatura, dando aula em cursinhos pré-vestibulares. E defini meu gosto pela profissão a partir do meu estágio supervisionado, em uma escola pública, no Colégio Estadual Manoel Ribas, o Maneco, à noite, em uma classe com quarenta alunos. Foi ali que eu me apaixonei definitivamente pelo ensino de filosofia. Trabalhei um ano no ensino médio, no então Colégio Agrícola da UFSM, com um contrato precário, e dali em diante não parei mais. Como eu conto no meu livro, na época eu havia lido o livro de Charles Postmann e do Neil Weingartner, "Contestação, nova fórmula de ensino" e eu procurei aplicar nas minhas aulas o que havia aprendido no livro. Assim, desde cedo eu procurei ter uma atitude reflexiva sobre meu desempenho em sala de aula. Mas isso só virou uma preocupação teórica séria e sistemática muito mais tarde, quando meus filhos cresceram e entraram para o ensino médio. Ali eu tive uma crise muito grande, pois ficava pensando se aquilo que fazíamos na Universidade, tanto nas aulas quanto no espirito da preparação de futuros professores, era de fato adequado aos novos adolescentes. E concluí que não. Acho que o que fazemos na universidade, em termos de preparação dos futuros docentes, é muito pouco e não muito bom. Exagerando um pouco, eu diria que o eixo da preparação teórica ainda é a história da filosofia e uma epistemologia tradicionalista, e o eixo da formação pedagógica ainda é um paulofreirismo descontextualizado, com pouco estudo de psicologia. Ainda estamos, nesse sentido, nos anos setenta do século vinte. Escrevi o Ensino de Filosofia e Currículo, que publiquei em 2008, para marcar uma posição que não quer negar o passado, mas que quer ir um pouco mais adiante. E agora quero 
avançar um pouco mais. No projeto que estou desenvolvendo, que é um livro sobre as relações entre filosofia e escrita, quero mais uma vez problematizar alguns temas de ensino de filosofia que considero ainda mal resolvidos, entre eles uma espécie de fazer que conta que não sabemos muito bem o que é isso que fazemos, no que diz respeito à identidade do ensino de filosofia.

Cláudia: Você acompanhou e participou do movimento de retorno da Filosofia ao Ensino Médio, poderia nos falar sobre este processo e nos apresentar sua leitura acerca do Ensino de Filosofia na atualidade, após os 7 anos de sua presença no currículo escolar? Quais são os desafios que temos, seja no âmbito dos cursos de licenciatura em Filosofia, seja no âmbito da Escola Básica brasileira?

Ronai: O tema é muito vasto, seria necessário fazer um longo ensaio para dar conta dessa pergunta. Vou tentar elencar os aspectos que me parecem mais relevantes. A história do movimento pela volta da filosofia ao currículo do ensino médio foi relativamente longa, começou nos anos setenta, muito em torno da SEAF, com nomes de peso envolvidos, como os de Marilena Chauí em São Paulo e aqui no Sul, o Valério Rohden. Muita gente esteve envolvida nisso e de fato o objetivo era que o ensino de filosofia fosse admitido no currículo escolar como um componente explícito e obrigatório. Poucas pessoas, da comunidade da filosofia, eram contra a presença da filosofia no ensino médio, mas não deixavam de haver vozes que questionavam um pouco o sentido do que ali seria feito. Hoje, passados sete anos, o que se pode dizer? Aqui eu só posso dar algumas impressões pessoais, pois não tenho andado quanto gostaria por esse Brasil. A primeira impressão é que não avançamos muito, em termos de cultura didático-pedagógica voltada especificamente ao ensino de filosofia. O que mais se produz em ensino de filosofia, ainda hoje, são reflexões de tipo literário, sobre as impossibilidades e possibilidades, segundo esta e aquela perspectiva, segundo esse e aquele autor. Há pouco trabalho intermediário. O pesquisador trabalha, digamos, com os teóricos franceses da moda - ou faz uma volta a Kant ou Hegel - dali já parte para alguma conclusão que não tem uma conexão efetiva com o cotidiano de aprendizagens de sala de aula. E mais do que isso, estamos flertando perigosamente com a produção de pensamento crítico por estampagem. Os livros didáticos de filosofia, por exemplo, 
estão cheios de páginas que tentam convencer o leitor-aluno das sacanagens do capitalismo neo-liberal e não trazem uma página de desmontagem de estruturas de argumentação. Não é raro que o livro didático de filosofia no Brasil não tenha uma única página sobre lógica e argumentação, mas que tenha muitos textos de crítica ao neoliberalismo, sem que fique muito claro em que isso - o neoliberalismo consiste. Isso é claramente um exemplo de pensamento crítico por estampagem, do tipo "pensem assim" que estarão no caminho certo. Ora, não me parece que seja este o sentido da presença da filosofia no currículo escolar. A gurizada está ali não para ouvir a nossa música e ser estampada por ela, mas sim para aprender a usar os instrumentos com que a tocamos. Nesse sentido eu acho que o ensino de filosofia ainda tem um longo caminho a encontrar, em primeiro lugar, para depois percorrer. Mas há muita gente fazendo um trabalho interessante, mais para o lado dos instrumentos do que para o lado da estampagem. O difícil, nesse outro caminho, é que quase tudo está por fazer, dada a nossa falta de tradição didática, dada a pobreza de nossa cultura curricular e pedagógica em filosofia. E desse quadro decorrem os principais desafios que temos. No âmbito da faculdades, temos que nos reinventar, olhar para a face do ensino médio e pensar no tipo de formação e conteúdos que são adequados. O caminho que costumamos fazer é o inverso, partimos de nosso universo de referencia para fazer no ensino médio uma espécie de versão diluída do currículo superior. Só esse fato bastaria para que a gente tivesse que admitir, nas faculdades, que não temos cultura curricular adequada para enfrentar o desafio a que nos propomos, de ter filosofia no ensino médio. Nesse tipo de gesto fica materializado nosso - eu digo aqui algo que acho que vale para nossa área como um todo - desconhecimento das diferenças estruturais entre a formação de ensino superior e a formação no nível médio. Desse tipo de atitude decorre um currículo de ensino médio que é apenas um aliviamento caricatural do ensino superior, que somente dá certo, quando dá, por conta da criatividade dos professores. Assim, temos que nos reinventar, nas faculdades, e pensar um currículo de formação que tenha mais atenção ao ensino médio e menos o olhar voltado para duvidosas tradições da própria área.

O segundo desafio, no âmbito da escola, é maior ainda, e depende de algum sucesso nesse primeiro nível, o da formação. Ele consiste na recuperação do 
sentido curricular da filosofia, menos como um dispositivo de estampagem enviesado pelas convicções pessoais do professor, e mais como um espaço genuíno de balança de argumentos, de apropriação de instrumentos de reflexão. $E$ tem ainda a questão da presença da filosofia como uma disciplina que explora dos espaços reflexivos implícitos no chão da escola, tanto no chão curricular quanto no chão institucional e social. É dessa dimensão que surge o que eu venho chamando de "transversalidade pedestre" a ser explorada na filosofia. Mas isso eu tratei longamente no "Ensino de Filosofia e Currículo", não quero repetir aqui.

Cláudia: Considerando a reforma curricular proposta para as DCNEM (2012) mais especificamente o currículo pensado por áreas de conhecimento, como você analisa este processo e quais implicações podes pontuar para a Filosofia na escola?

Ronai: Vou deixar de lado o fato que tenho um certo ceticismo sobre a aplicação imediata das Diretrizes de 2012. A previsão de horas-aula adicionais que elas fazem é incompatível com a atual crise das universidades federais. Só na UFSM são necessários professores para mais umas quatro mil horas aula. Deixando isso de lado, quero dizer apenas duas ou três coisas. A reforma proposta poderá ser resolvida de forma mais ou menos tradicional, com o currículo ainda centrado no componente específico, ou ser feita de modo radical, oferecendo licenciaturas por áreas de conhecimento. O MEC já aprovou, para o estado de São Paulo, um projeto de licenciatura que tem quatro cursos. Um deles em Linguagens, outro em Ciências da Natureza, outro em Ciências Humanas e outro em Matemática. Da forma com eu entendo, isso não é obrigatório, os cursos centrados em componentes também são contemplados. E nesse caso a organização por áreas de conhecimento será mais sutil e em muitos casos nem haverá, ficará apenas no papel. No sentido teórico mais amplo, o esforço de pensar o currículo por áreas de conhecimento demorou mais de trinta anos para chegar ao Brasil. Isso é quase tão velho como as pedras. E o fato de ter demorado tanto deveria ser visto como mais um sintoma da penúria do pensamento curricular brasileiro. Enquanto o tema tem quarenta ou cinquenta anos de tratamento na Inglaterra, na França, nos Estados Unidos - digo isso de um ponto de vista da discussão teórica, e não exatamente de 
aplicações reais, pois aí creio que apenas a Inglaterra saiu mesmo na frente - aqui no Brasil ainda pensamos o currículo focados apenas nas corporações disciplinares. Veja bem, ainda não foi inventado - e nem será - nada melhor do que cada uma das disciplinas escolares fundamentais. Simples assim. Sempre houve e sempre haverá alguma matemática e alguma linguagem, e conhecimentos do mundo natural e do mundo social, etc. As disciplinas fundamentais são, por assim dizer, feitas de pedra dura que resiste qualquer água. Mas isso é apenas um fato trivial, que diz respeito às estruturas fundamentais da curiosidade humana. E este fato trivial, da irredutibilidade das disciplinas, precisa conviver com outro fato, ainda mais trivial: o currículo, que é aquilo que conta como o conhecimento valioso, é uma espécie de narrativa dos tesouros cognitivos da humanidade. E, como uma narrativa, é algo que deve ser costurado em blocos maiores do que esta e aquela disciplina. Assim, a demanda para se pensar o currículo por áreas de conhecimento é, a meu ver, uma demanda-sintoma corretíssima. Isso me leva ao segundo ponto da pergunta, sobre as implicações que isso pode trazer para a Filosofia na escola. A meu ver, essas implicações são água para nosso moinho. Nenhuma disciplina escolar tem a potencia que a filosofia tem para transitar dentro e entre as diversas áreas do conhecimento curricular. Desde o velho Aristóteles é claro para nós que a filosofia pode explorar a dimensão reflexiva de cada cantinho da experiência humana. Desde o primeiro semestre letivo o aluno de filosofia aprende que existe, de pleno direito, uma filosofia da arte, uma filosofia das ciências, uma filosofia da historia, uma filosofia da linguagem e assim por diante. Ora, o currículo escolar é cheio desses pequenos espaços reflexivos. Todas e cada uma das disciplinas escolares - mas não só isso, todos e cada um dos aspectos das vivencias e realizações do estudante dentro de uma escola - tem aspectos reflexivos que usualmente são desprezados pelo professor da área. Um professor de física pode não querer discutir uma noção como a de "causalidade" ou a de "lei", pois isso não é operacional em seu currículo. Mas se o professor de filosofia não fizer isso, quem o fará no currículo? A meu juízo, as implicações dessa demanda por áreas e interdisciplinaridade é uma grande oportunidade de presença da filosofia no currículo escolar que poderíamos ter. 
Cláudia: Seu livro, lançado em sua segunda edição no mês de outubro, trata de algumas temáticas caras aos futuros professores de filosofia. Você apresenta sua perspectiva acerca da interdisciplinaridade e transversalidade no currículo. Como você avalia a sua repercussão para os professores e futuros professores.

Ronai: Aqui eu sou suspeito, posso me deixar levar por um otimismo irreal. Mas o fato de que a primeira edição do livro esgotou-se, somado ao fato que o livro tem sido gradativamente indicado como leitura recomendada em disciplinas de prática de ensino e em concursos para docência sugere, para mim, que o livro gerou, desde a primeira edição, em 2008, um certo espaço de recepção. Eu gosto de brincar com a afirmação de que não é difícil escrever um livro, e se ele for razoável, não é difícil que ele seja publicado. Eu não tinha nenhum contato na Vozes, ela decidiu publicar o livro depois de lê-lo. O mais difícil é achar leitores. E isso foi acontecendo aos poucos, a primeira edição esgotou-se ao longo de sete anos. Foi devagar, mas aconteceu. Alguns projetos do Pibid, por exemplo, o da Universidade Federal do Rio Grande do Sul - que é um projeto especificamente voltado para a construção de uma proposta interdisciplinar - tem usado o livro como uma inspiração, para minha alegria. Eu tenho acompanhado esse trabalho - que foi proposto pela Professora Gisele Secco - e ali consigo ver uma boa repercussão do livro. No encontro nacional do Pibid que houve em Goiás, faz alguns anos, eu tive noticias de outros grupos que tem incluído o debate do livro como parte de estudos curriculares. Não é raro que ex-alunos meus me contem que usam o livro, aqui e ali. Assim, creio que aos poucos o livro vai fazendo seu publico. Houve alguma incompreensão - creio que até hoje há - em relação a algumas das ideias que apresento ali, pois o livro sai um pouco para fora da caixa tradicional das discussões sobre ensino de filosofia, pela maneira como tematizo a transversalidade. Mas aos poucos ele vai se firmando. E agora temos a segunda edição.

Cláudia: Quais são os autores que te auxiliam a pensar sobre as questões de currículo, ensino e aprendizagem de filosofia para jovens/adolescentes no ensino médio? 
Ronai: Vou tentar indicar aqui os principais nomes. Como eu já disse antes, até hoje eu me sinto marcado pelas leituras de Charles Postmann e Neil Weingartner, em especial no que diz respeito na reflexão sobre a pedagogia. Mas isso foi uma leitura dos anos setenta. A minha formação foi muito caótica e sempre dependente de coisas muito casuais. Tive a sorte de estudar numa universidade na qual havia um mestrado sobre currículo com o qual convivi muito, a Faculdade Interamericana de Educação, também nos anos setenta. Foi a partir desse convívio que eu pude vivenciar diferentes etapas do pensamento pedagógico brasileiro, desde os enfoques da pedagogia a partir da teoria da informação, no começo dos anos setenta, passando pelos estudos curriculares clássicos, com as leituras de Hilda Taba e depois pelos enfoques sobre reprodutivismo e antropologia aplicada à educação. Depois de uma crise pessoal muito forte fiquei um bom tempo afastado desses temas. Eu me meti em administração universitária na metade dos anos oitenta. Fui pró-reitor de graduação da UFSM durante quatro anos e isso me deu uma visão muito mais realista da universidade e da educação. Reencontrei as questões de currículo depois de colaborar por um bom tempo com o grupo de pesquisadores liderados pela professora Esther Grossi, do GEEMPA, de Porto Alegre. Foi ali, junto a um trabalho no chão de escolas que me levou até mesmo para atividades de formação no Cabo Verde, na África, que recuperei o gosto por questões de didática e formação que eu tive no início de minha vida profissional. Foi nesse momento que eu comecei a fazer conexões internas entre certas abordagens da filosofia, da psicologia e da didática. Aprendi muito com Gerard Vergnaud, um dos grandes nomes da didática de Matemática, na França, que esteve conosco no Geempa, em Porto Alegre. Foi com Vergnaud que eu me dei por conta do atraso da didática brasileira, pois era muito flagrante a defasagem de referenciais. Enquanto nós aqui no Brasil até hoje usamos a literatura de sociologia da educação dos anos setenta, Vergnaud, sem desprezar esses enfoques, nos trazia uma didática que dialogava, por exemplo, com a melhor filosofia da linguagem disponível. A filosofia da linguagem até hoje é uma ilustre desconhecida nos currículos das faculdades de educação. Depois de trabalhar bastante com currículos e aprendizagens nas séries iniciais, comecei a pensar sobre como seria uma discussão dos aprendizados de filosofia no ensino médio. Foi nessa época, na metade dos anos noventa, que comecei a me ocupar com as ideias que depois 
convergiram para o "Ensino de Filosofia e Currículo". Foi nessa época que percebi que a didática francesa fazia um uso intenso de categorias filosóficas - de Frege, por exemplo - e linguísticas, como as de Saussure. Aí meu caiu a ficha, pois percebi que a renovação da didática vinha de muitos lugares, mas, em especial, da própria filosofia. E, é claro, muita leitura dos clássicos da psicologia, Piaget, Vigotsky, Wallon, mas também Winnicott. Winnicott, para mim, é essencial, como procurei mostrar no livro. Nos últimos tempos tenho incorporado as reflexões de Basil Bernstein. Bernstein é um caso interessante. Há apenas um livro dele traduzido aqui no Brasil. Seus textos mais relevantes, em especial os textos dele que mais tiveram influência sobre a nova sociologia da educação não estavam disponíveis entre nós. Eu me refiro ao escrito sobre classificação e enquadramento do conhecimento e o outro, sobre a distinção entre discurso horizontal e vertical. Traduzi esses dois artigos no ano passado, para usar nas minhas aulas. É inexplicável - eu diria que é trágico - essa lacuna, essa ausência dos textos de Bernstein. Para se entender um pouco melhor a crise que passamos na educação, é preciso ler Bernstein. Nessa lista preciso acrescentar mais um parceiro de caminho, que é o Michael Young. Não por acaso Young também está na origem das grandes transformações conceituais da teoria curricular no século vinte. E agora ele tem escrito uma série de artigos fundamentais para o tema da inclusão educacional com qualidade. Mas a espinha dorsal do que eu tento fazer é da filosofia. Sem a formação filosófica para dar uma direção, essa lista de autores é apenas uma lista. Acho que eu tento ver, digamos assim, as dimensões reflexivas de cada um deles. Por exemplo, para que a gente possa ler com proveito a produção de didática na França - Gerard Vergnaud, por exemplo, é preciso conhecer um pouco de Frege, de filosofia da linguagem. Para se tirar o melhor de Vigotsky é muito bom você ter algum conhecimento de Wittgenstein, e sem Kant não se entende bem a psicologia do Henry Wallon. Mesmo o caso do Piaget, como se pode entender o projeto dele se não temos presente as relações de Piaget com a filosofia, na linha do que ele escreve em "Sabedoria e llusões da Filosofia"? Mas hoje em dia estou incorporando uma nova lista de autores, para o projeto que venho desenvolvendo desde o início deste ano, que é um trabalho sobre as relações internas entre filosofia e escrita que já está bem adiantado. 
Cláudia: Como você avalia o atual momento da educação brasileira e em especial do ensino de filosofia. Quais são as perspectivas que podes indicar? Como você avalia a formação dos futuros professores de filosofia em seus cursos de licenciatura?

Ronai: $\bigcirc$ que se pode dizer sobre uma questão assim tão vasta, como o estado da educação brasileira? Há alguns sentidos em que estamos bem. Eu, por exemplo, sou de uma época em que se fazia exame de admissão para a continuidade dos estudos básicos. Quem não passava abandonava a escola, com certa naturalidade. Isso ocorria no Brasil até os anos setenta. Hoje, em princípio, há escola para todos. Vamos indo razoavelmente bem no quesito inclusão, que foi o grande desafio desde o fim do exame de admissão, que marcou exatamente o surgimento no Brasil desse processo. Mas esse é apenas um dos sentidos da palavra inclusão, o sentido quantitativo. Mais de oitenta por cento dos estudantes brasileiros estão em escolas públicas, e a escola publica tem muitos problemas com relação à qualidade, seja de instalações, seja de aprendizagens, tem muitos problemas de relação idade e série e por aí vai. Uma das razões pelas quais isso aconteceu é que não é nem fácil e nem simples fazer inclusão com os mesmos padrões de qualidade da escola anterior, de elite. Um sintoma e uma consequência disso é o progressivo abandono da escola publica pela classe média. O mesmo professor universitário que fazia greve em defesa da expansão da universidade retirava seu filho da escola publica na qual ele mesmo havia estudado. Hoje a escola publica luta por melhores padrões de qualidade, pela recuperação de uma cultura didática e curricular que foi perdida nos corredores da historia educacional brasileira recente. Na ocupação de escolas que ocorreu em São Paulo, em novembro desse ano, os jornais destacaram a declaração de uma menina que comparou sua escola, que estava precisando de reformas, das "escolas dos ricos", que desfrutavam de segurança, bons prédios, e, principalmente, professores assíduos. Principalmente em centros urbanos maiores, temos dois sistemas diferentes entre si, em especial no que diz respeito à condições materiais, planejamento curricular e assiduidade docente. Só que a qualidade da escola privada vem sendo obtida por meio de estratégias de planejamento vertical, adotando o sistema de franquias de ensino, por exemplo. O quadro é muito preocupante. E de outro lado está aquilo que 
venho chamando, faz algum tempo, de "perda da cultura pedagógica". Os departamentos que deveriam fazer pesquisa didática estão muito ocupados, ainda, com temas de filosofia, sociologia, antropologia e política da educação. Não existe mais pesquisa em didática. Ela foi literalmente abandonada, trocada por um "paulofreirismo" cada vez mais diluído, que é incapaz de fazer frente ao cotidiano da sala de aula. Não podemos criticar apenas os chamados "departamentos de conteúdo", como o da filosofia, pois na pedagogia, como um todo, também se vê uma preferência por estudos mais conceituais e menos de sala de aula. O ensino de filosofia está no meio dessa corrente, não somos nenhum ponto fora da curva. Enquanto não houver uma retomada de um trabalho mais miúdo, de pesquisa didática e curricular, de produção de pedagogia a partir de um referencial mais afinado com o chão da escola, as perspectivas serão modestas. E, é claro, tudo isso tem que ser feito em um processo combinado com a academia como um todo, com mudanças nos cursos de formação, na chamada "formação específica", mas também na dimensão pedagógica, que na atualidade é demasiadamente teórica, por assim dizer. $O$ que eu quero dizer aqui é que as pessoas se dedicam mais aos grandes temas da política do que aos pequenos temas da gestão da aprendizagem e do conhecimento em uma escola. Assim, no processo formacional em nível superior, há problemas sérios. Os chamados departamentos de conteúdo não costumam desenvolver as aulas e os conteúdos com uma preocupação com a recontextualização daquilo que está sendo estudado. O professor de conteúdo parece não fazer nenhuma diferença entre trabalhar no bacharelado e na licenciatura. E os assim chamados departamentos de educação parecem mais interessados em discutir teorias filosóficas sofisticadas do que fazer pesquisa em didática, recontextualização, transposição, habilidades de sala de aula, enfim, com a criação e recriação do saber didático efetivo, de chão de escola.

Cláudia: Para finalizar, qual sua análise sobre o PIBID a partir de tua experiência como coordenador em quase dois anos, na UFSM? Quais as contribuiçōes que o PIBID tem trazido para a formação inicial e continuada de futuros professores e de professores em exercício? 
Ronai: O Pibid é o acontecimento mais relevante na vida das licenciaturas desde muito tempo. Há, de um lado, a sinalização, com a bolsa, pelo interesse pela formação, com o apoio material para a permanência do aluno. O Pibid surgiu ligado ao diagnóstico do apagão de docentes em certas áreas do currículo, e tornou-se uma gigantesca ferramenta de formação, atingindo quase cem mil licenciandos. Seria de se esperar que o Pibid se firmasse como uma política, que fosse universalizado, dadas as boas repercussões. Ele tem sido um novo e rico espaço para o processo de formação, num formato que contribui para o enriquecimento das relações entre a escola e a universidade. É difícil exagerar a importância do Pibid, e é isso que faz com que a atual crise que ele atravessa, com o congelamento do numero de bolsas, seja muito preocupante. O Pibid é, no momento, a única política pública que ativa a autoestima dos licenciandos, e porisso sua contribuição para o processo formacional é inestimável. Eu torço para que ele continue.

Prof. Ronai Pires da Rocha Professor Associado Departamento de Filosofia - UFSM 